\title{
A REGENERATION STUDY OF REPRESENTATIVE LOGGED-OFF LANDS ON VANCOUVER ISLAND

\author{
By GoRDON GoDwin
} \\ Forest Surveys and Working Plans Division, B. C. Forest Service.
}

\section{INTRODUCTION}

$\mathrm{D}$

URING 1936 the Forest Surveys Division made a general investigation into the condition of logged-off lands on Vancouver Island within the boundaries of the Esquimalt and Nanaimo Railway Land Grant. The result of this survey indicated that only $24 \%$ of the logged lands were satisfactorily restocking. Excluding areas affected by logging or fires during the past 10 years, $45 \%$ of the cut-over lands are satisfactorily stocked. These figures indicate, either that a period of at least 10 years is required before new growth becomes established to an appreciable extent, or that this great difference in the percentage of area stocked is largely attributable to the fact that during the past decade or so, an increasingly large proportion of our annual cut-over acreage must be credited to the activities of large operators, who each year cut over such an expanse of ground that restocking from marginal timber becomes impossible for all but a small percentage of the area. To make more specific research into these questions was among the purposes of the study herein reported.

In the summer of 1937 this study was undertaken on the logged-off lands of a representative large logging company near Campbell River, and the east coast of Vancouver Island. The study area lies wholly within the territory known as the E. and N. Belt, and comprises 21,000 acres. This land was originally covered by a fine stand of Douglas fir, with relatively light admixtures of western red cedar, and western hemlock, yielding a timber volume of approximately 50,000 f.b.m. per acre. These lands were examined for the purpose of determining with what degree of success new forest growth was establishing itself, and if possible, defining causes for the conditions found.

\section{METHOD OF INVESTIGATION}

The method of examination differed from any yet applied in studies of a similar nature in British Columbia. The procedure was to establish lines of plots, each plot being in the form of a quadrat 13.2 feet square, the equivalent of $1 / 250$ of an acre. The stocked quadrat method of sampling was refined somewhat, in that each quadrat was not merely checked as being stocked, or unstocked, but the number of seedlings from 0 to 7 were indicated. By this means we recorded not only the varying degrees of stocking 
below that of satisfactory, but data upon stocking greater than now considered adequate. This may prove valuable if in the light of future knowledge we should have to revise our conception of what constitutes adequate stocking. The lines of plots were spaced generally at intervals of 10 chains. This interval was varied at the discretion of the examiner, as was the spacing of the quadrats on line. On occasion these were placed at 2 chains rather than at 1 chain intervals. In this manner examination was made to a degree of intensity varying from $1 / 50$ of $1 \%$ to $4 / 10$ of $1 \%$. When reproduction occurred under conditions promising reward for study, or when the occurrence of reproduction was irregular, examination was most thorough. On large areas affected by easily discernible factors with uniformity in occurrence of reproduction the minimum of quadrats possible was recorded. The judgment of the examiner in placing lines of plots was verified from time to time by statistical analysis of the data obtained.

All types were recorded on a map drawn to a scale of 20 chains to the inch, topography being taken with a contour interval of 20 feet. Vertical control was available in the form of level notes taken by company engineers in conjunction with their railroad location. This information was supplemented by the use of aneroid barometers. Vertical and horizontal control was carried on strip lines by means of topographical abney, chain and box compass. In the preparation of the map the Forest Service is indebted to the logging company in question which supplied information in the form of maps indicating the progress of logging, by dates and volume removed for each setting. At all times during the progress of the study, the company was most willing to assist in any way possible.

DENSTTY OF STOCKING

In accordance with the degrees of density of stocking accepted as standard for the E. and $\mathrm{N}$. Survey as a whole, the accompanying tables are based on the following schedule:

\begin{tabular}{|c|c|c|c|c|c|c|}
\hline \multicolumn{7}{|c|}{ Number of Trees per Acre } \\
\hline & & & Satisfactory & Fair & Poor & Nil \\
\hline Age & $1 \cdot 10$ & years.... & $1,000+$ & $400+$ & $50+$ & $50-$ \\
\hline & 11.20 & $" \ldots$ & $750+$ & $300+$ & $50+$ & $50-$ \\
\hline$"$ & $21-30$ & $"$ & $425+$ & $200+$ & $25+$ & $25-$ \\
\hline$"$ & $31-40$ & $"$ & $425+$ & $150+$ & $25+$ & $25-$ \\
\hline
\end{tabular}

Table 1 is a statistical picture of the present condition of the area examined. It shows for each acreage logged by years, the number of acres re-stocked by species, and under the column "Logged and Burned, Re. burned," indicates in the acreage affected the reasons for the failure of the 
area to restock. Here we see in the total acreage logged (19,981 acres) 2,077 acres have been burned three or four times since logging. Attention is drawn to the figure of 589 acres of satisfactorily stocked under the heading of "Logged." Without explanation it would appear that $55 \%$ of the fully stocked area is found on lands on which the slash has not been burned. True enough the slash is unburned, but the reason for the reproduction is that prior to logging, fire had run over the ground surface, destroying the duff and exposing the mineral soil. On land not touched by fire either before or after logging, in no instance was there satisfactory reproduction. It must be borne in mind however, in drawing the evident conclusion of reproduction being more successful on burned than on unburned lands, that, excluding logging done in the past 3 years, the case for the unburned land is based on but 755 acres, against 15,468 acres of logged and burned land examined. The occurrence of reproduction in unburned slash, the cause for which is definitely due to a surface fire having run through green timber prior to logging, leads one to question conclusions drawn from previous studies which have stated reproduction to be more plentiful in the unburned slash, than on slash burned areas. It is possible that when the original stand has been Douglas fir, further investigation of the history of previously studied areas may show the reason for the prevalence of reproduction in slash to be the occurrence of a ground fire through the timber a few years before logging.

Table 2 is derived in part from Table 1, segregating the data into three periods, and further classifying the area unsatisfactorily stocked into fair, poor and nil.

Table 3 is a refinement on Table 2, in that, although the species classification is dropped, acreages are now shown not merely by logging dates, but rather as they were affected by the last major factor influencing them whether logging or fire. Thus in Table (b), in the period 1928-32, some areas logged in 1921.27 are included since they were last swept by fire in 1928-32. Presented in this light it is seen that for this period the percentage of satisfactorily re-stocked becomes $3 \%$ rather than $7.5 \%$ as is the case when division of area is made by logging dates. Similarly the percentage of the area containing no stocking, when causative factors are considered, becomes 68 rather than 58 . This clearly shows the effect of repeated fires, some 4,000 acres having been burned two or more times. 
64

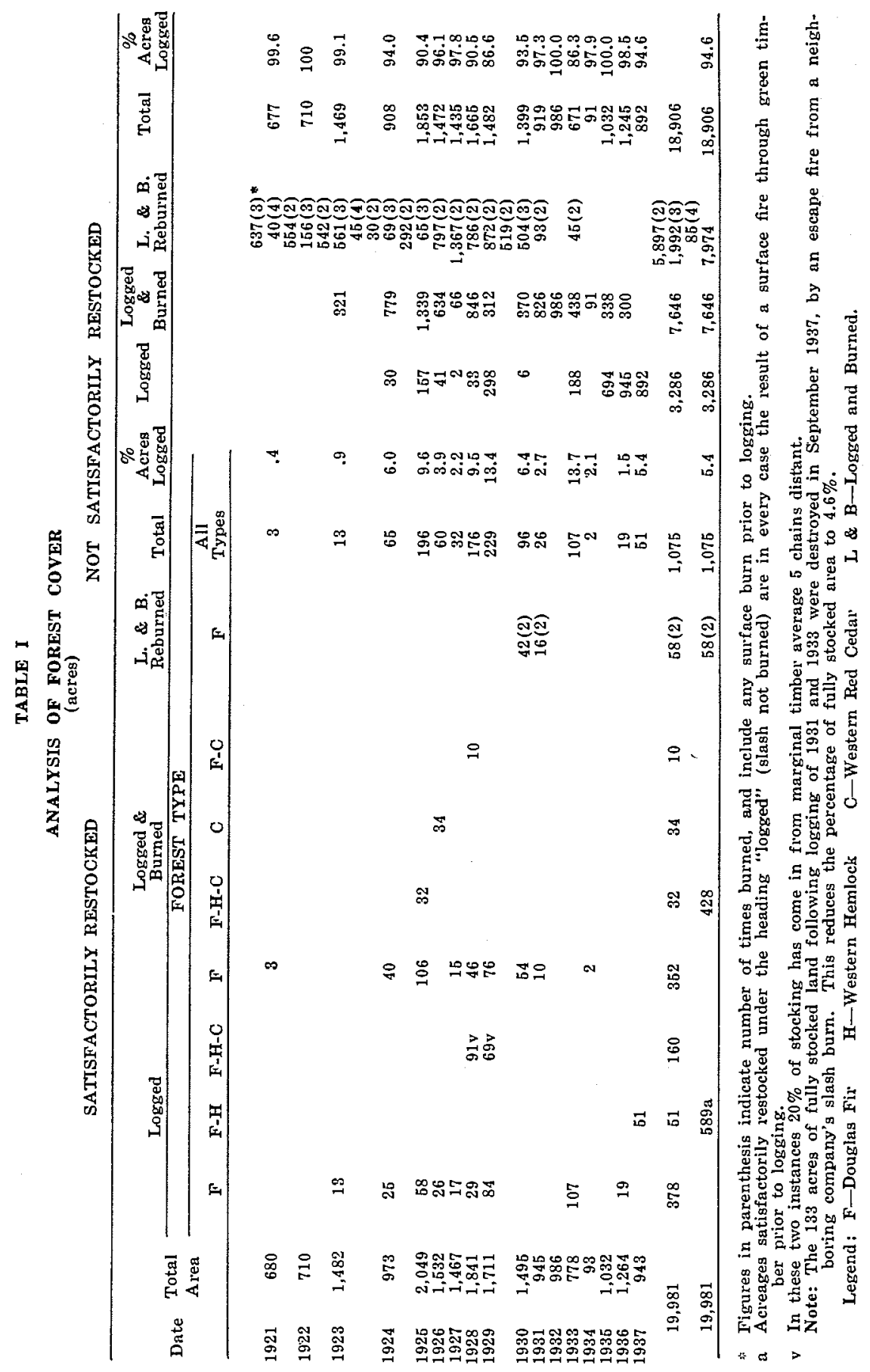


REGENERATION STUDY_GODWIN

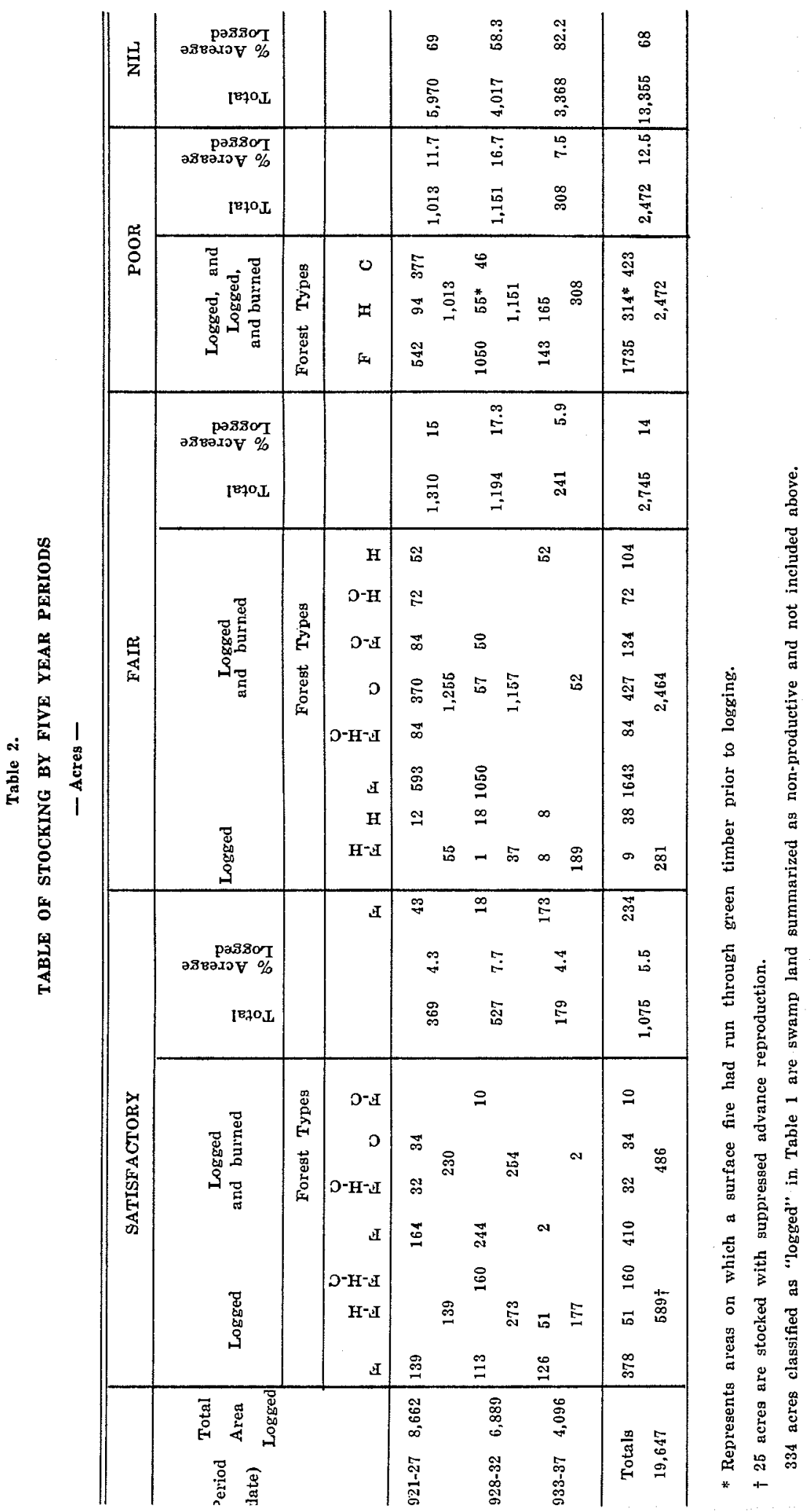


TABLE 3

Tables of Stocking as Affected by Fire History

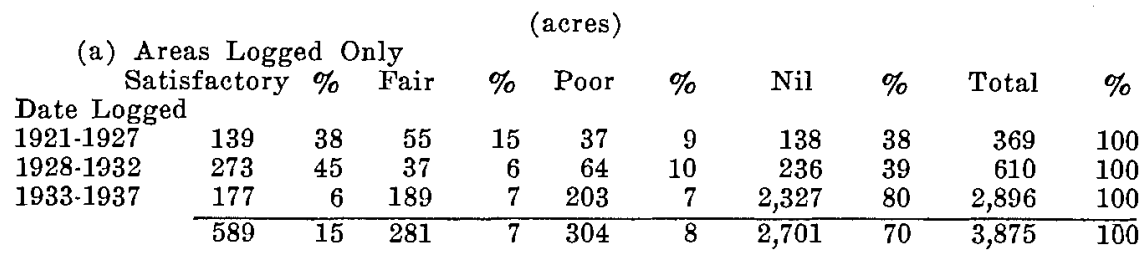

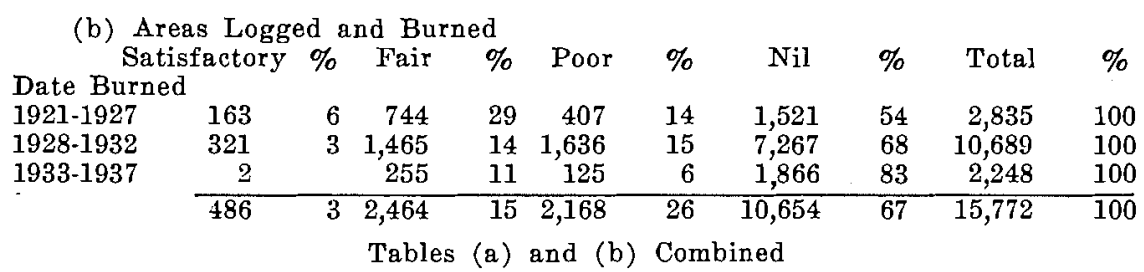
Date logged

(c) Areas Logged, and Logged and Burned. Satisfactory $\%$ Fair $\%$ Poor $\%$ Nil $\%$ Total $\%$ or burned.

$\begin{array}{rrrrrrrrrrr}1921-1927 & 302 & 10 & 799 & 25 & 444 & 14 & 1,659 & 51 & 3,204 & 100\end{array}$ $\begin{array}{lllllllllll}1928-1932 & 594 & 5 & 1,502 & 13 & 1,700 & 15 & 7,503 & 67 & 11,299 & 100\end{array}$ 1933-1937

$\begin{array}{rrrrrrrrrr}594 & 5 & 1,502 & 13 & 1,700 & 15 & 7,503 & 67 & 11,299 & 100 \\ 179 & 3 & 444 & 9 & 328 & 6 & 4,193 & 82 & 5,144 & 100 \\ 1,075 & 5 & 2,745 & 14 & 2,472 & 22 & \mathbf{1 3 , 3 5 5} & 68 & 19,647^{*} & 100\end{array}$

*334 acres classified under "acreage logged" in Table 1, are swamp land: summarized as non-productive and not included above.

\section{FACTORS AFFECTING THE SUCCESS OF REGENERATION}

(1) EFFECT OF LOGGING

Logging throughout progress of the liquidation of the timber on this tract, has been with minor exceptions in the past three years, by means of an overhead cable system. $12 \times 12$ steam Lidgerwood tree-rigged skidders have been in continuous operation, being used almost entirely as yarders, a minimum of swinging being necessary. In latter years as logging progressed from the flat benchlands to the more broken hillsides, an increasing amount of cold decking long corners has been done. Yarding distances with the skidders are rarely greater than 1,000 and often not more than 700 feet. The result of such comparatively short distance yarding is surprisingly little soil disturbance. This factor of soil disturbance by logging is important in that during good seed years, seed in the slash will germinate in mineral soil exposed-the more soil exposure the more reproduction. It is estimated that for this operation, on good ground when yarding was easy, only from $10.15 \%$ of the ground surface had been broken to expose mineral soil. As the ground to be logged becomes rougher, soil disturbance is greater, and 
the chance for reproduction better. On a portion of the study area where soil disturbance was considerably greater, patches of fir reproduction occur where they had been missed by the slash burn of 1934. 1932 and 1933 were good seed years. It is probable that a good portion of the area was fairly well stocked, and that the burn over the area was ill-advised.

Further evidence of how lightly this skidder logging affects the soil surface, is found on those areas where reproduction was established before logging. Only on the yarder roads themselves, and on a roughly circular area with a radius of 150.200 feet from the head spar, where yarder roads converged, was the reproduction totally destroyed. On the remainder of each setting the bulk of the reproduction was unharmed.

The major part played by logging as a factor working against the success of reproduction lies in the expanse of territory which is cut over each year. Every year some 1,500 or more acres are laid bare, and although this area is generally broken into from two or six individual logging shows, there is no possibility of marginal timber seeding in areas of such size. The chance of such an event happening would be increased if each year's slash, where warranted, was promptly burned. But this has rarely happened. Usually the accumulation of two or three years' logging is burned at once, by which time the margin of the timber may lie three quarters of a mile, or more, from land for which it is the only source of seed.

(2) EFFECT OF FIRE

To burn or not to burn is a problem which excites animated argument among foresters whenever the question of slash disposal is raised. Within the profession, advocates for one policy or the other have been so divided in their opinions on the silvicultural questions involved, that the men responsible for the creation of the slash can soundly argue, that if the experts can't agree among themselves, there is little that the logger can do. Now we are realizing that it is equally foolish to condemn or advocate in principle, but that the problem of slash disposal on each operation merits individual investigation, and that local conditions determine the advisability of burning.

For the area with which this study is concerned, the absence of repro. duction in unburned slash, in one instance within two chains of green timber, on ground logged in 1929, gives cause to state definitely that in this locality, for similar timber types, slash should be burned. The sample area of unburned slash is admittedly small, but its component parts are well scattered over the study area and are consistent in their failure to show reproduction. 
It cannot be too strongly emphasized that any data presenting a comparison of regeneration on burned and unburned logged lands must be viewed in the light of local causative factors, bearing in mind that findings on this study will not necessarily apply under conditions when the ratios of these factors are changed, or when new factors enter.

These remarks have been qualified earlier in this article, when it was pointed out that reproduction has succeeded in unburned slash, but always as a result of a surface fire before logging. This reproduction is in some cases pure fir, in others hemlock, or cedar, or sometimes a mixture of all three. The degree to which the stand has been opened up by fire determined the composition of the stand. Where the fire, judging by the burning of the stumps, and in the memory of men who had logged the area following the burn, had been more intense-enough to kill one-third or more of the trees, fir reproduction predominated. Where the fire was evidently light, barely scorching the stumps but burning down to mineral soil, hemlock or cedar-sometimes a mixture of both-is in evidence. In all cases the composition of the original stand varied little, averaging $75 \%$ Douglas fir, the remainder cedar, with an occasional hemlock.

The actual result achieved by the fire, in the picture of the stand presented before logging, was similar to that which might be expected were the stand to be logged selectively with tractors. The action of the tracks of these machines would, as the fire did, disturb the litter and duff, exposing the mineral soil. The type of reproduction gained would largely be determined by the degree to which the canopy was opened in the first cut. Following successive cuts as the stand thinned out, any gaps in the first established reproduction might be expected to come in with fir. The logging slash is there as a fire hazard. So is it on the areas which prompted this discussion and surely no one would recommend burning slash on such areas fully stocked. The argument will be used that in the selection cutting the slash constitutes a danger not only to the reproduction but to the standing timber. But if we attain the end desired of establishing successive crops, the actual monetary gain in having our forest lands in production will warrant expenditure on the extra protection necessary. In addition, any selection cutting plan would make provision to break up the selection area with clear'cut strips, which after slash burning, would act as fire guards.

In the main the effect of fire upon the lands examined has been disastrous. There is no doubt that under present methods of cutting the best way to obtain reproduction is to burn each year's slash to the margin of timber. It has been noted there are exceptions to such a rule but on the 
whole yearly burning should be the policy. It has previously been remarked that this is seldom done. Unfortunately in most instances when reproduction has probably come in following a slash burn, it has been de. stroyed by a later fire.

In these remarks on the effect of fire, no opinion is offered concerning the relative merits of spring or fall slash burning. On the lands examined, intentional fires were always set in the autumn, and no opportunity was afforded for observation of the effect of slash burning in the spring.

It must be understood that while yearly burning when justified is advocated, this in itself will not ensure adequate restocking on the burned. over area. Such practice will simply increase the percentage of land satisfactorily stocked. For example, the logging company had by October 1st, completed 943 acres of 1937 logging. If the ground had been slash burned, presuming a good seed year, with other conditions at their optimum, we can, on the basis of past experience, assume seeding in would be successful for a distance of 10 chains from green timber. In this case $38 \%$ of the area would have been restocked, which is far from satisfactory. (Actually, had the slash been burned, none of the area would have restocked-the seed crop for 1937 in this district being a total failure.) It is evident that to burn each year is but one factor in the institution of better forestry prac. tice in the fir belt. The next measure necessary is to reduce the size of areas clear cut to a point where adjacent seed trees can adequately reseed the ground.

(3) EFFECT OF VARIOUS TYPES OF SEED SOURCE

(i) Marginal timber

Apart from reproduction resulting from ground fires through green timber before logging, the most successful young growth has come in from seed cast from marginal timber when this has consisted of healthy mature trees. Younger stands may be just as effective seed producers, but the opportunity was not available to verify this on the area under study. The extent of area which may be expected to restock from seed cast by marginal timber depends on three factors:-

\section{(a) Condition of area to be restocked}

Where the slash was not burned, reproduction has been unsuccessful due to the apparent inability of the seed to germinate under the adverse conditions existing in the seed bed of undisturbed (or very lightly disturbed) litter, moss and duff. This latter is an inch to three inches thick sometimes tending to a raw humus condition. When germination is successful, and 
the seedling has managed to get its roots down through the duff into min. eral soil, it seldom survives the intense competition offered by the heavy cover of Salal (Gaultheria shallon), bracken (Pteris aquilina), blackberry (Rubus macropetalus) and minor plants which grow in profusion among the unburned slash.

(b) Direction and velocity of the wind

Many studies have been made on the distance to which effective seeding may be expected. Isaac, studying Douglas fir, states that areas may be expected to seed up for a distance of 20 chains from green timber. 'In the case of the study area, restocking is rarely satisfactory to distances beyond 10 chains, even in the direction of the prevailing northerly winds. In direction opposite to that of the prevailing wind satisfactory reproduction extends for but 2 to 5 chains from the edge of timber.

(c) Occurrence of seed years.

This factor is of importance in that if a good seed year should fail to occur within three years of the burning of the slash, the ground surface, burned clean to mineral soil, becomes occupied by a moss (Polytrichum juniperinum) which, though it may sometimes permit the germination of seed falling on it, is generally effective in preventing survival.

It has been suggested that for certain locations on Vancouver Island, even when a seed supply is assured, that there may be a time-lag of a number of years following the burning of the slash until the density of stocking becomes satisfactory. An explanation given is that the severity of the fire so reduces the soil constituents necessary for plant growth that many years must pass before decomposition of detritus builds up the soil to a point where it can support a satisfactory number of trees. Admittedly without basis in observation, or experiment, the writer proposes that when a period of years is necessary to build up stocking to adequacy, causes other than soil conditions, notably the moisture factor, and insolation, are more likely to be responsible for the condition found. Short of actual erosion it is probably unusual for a coastal forest soil to be so damaged by fire that tree growth is prohibited. If the fault lies with moisture, heat, or a combination of both, silvicultural treatment along selection lines is indicated. In any case it is felt that too much importance, on too little evidence, has been attached to the theory that it takes ten years for reproduction to become established. Within a reasonable distance from the seed source, such was not found to be the case on the study area.

IIsaac, L. A. "Measured Flight of Seed of Douglas Fir and Its Associates." Pacific Northwest Experiment Station, 1928. 
The effect of burning on forest soils is a subject demanding immediate research. A valuable contribution to knowledge in this field has been made by Isaac and Hopkins, ${ }^{1}$ but much remains to be done. The institution of studies of this nature is of particular importance in view of the programme of supervised slash burning which the Forest Service has undertaken.

The occurrence of good seed crops following a fairly well defined cycle has been noted by a number of investigators for a variety of species. Sudworth ${ }^{2}$ states that maximum! seed years for Douglas fir occurs at intervals of 3 to 4 years. Isaac ${ }^{3}$ in 1928 reported a heavy crop of fir seed produced every four years. In $1937^{4}$ the same investigator modifies this statement to read that bumper Douglas fir crops occur from 3 to 7 years apart. Inspection of the seed crop history for the study area over a period of 14 years fails to disclose the appearance of any cycle, which is unfortunate in that a haphazard distribution of adequate seed crops, with sometimes years of near or total crop failure, adds to the complexity of management problems. Europeon research ${ }^{5}$ indicates in many instances that prolific seed years occur a year, or two years, after a hot, dry summer. This type of weather favors a quickening of those processes within the tree dealing with the production of carbohydrates, thus producing an excess of these nutrients over the salts absorbed from the soil. This surplus is expended by the tree in the form of seed production. Records dealing with conditions on the study area, in the matter of seed year history, and of climate, are neither extensive enough, or sufficiently reliable, to warrant conclusions being drawn along similar lines, but they do indicate the possibility of a similar sequence of events for our species. For instance, the good seed year of 1923 was preceded by a hot, dry summer in 1922. The period of good seed years 1931 , '32, and ' 33 followed years in 1929 and 1930 wherein annual precipitation fell respectively 19.15 inches and 12.65 inches below the 13-year average. This coincidence is unusual enough to warrant analysis of similar records for other regions in an effort to unearth further evidence having a bearing on this subject. Factors other than the occurrence of hot, dry summers in the year preceding that of crop production will complicate such an investigation. Spring frosts, or protracted periods of wet weather during

\footnotetext{
1Isaac, L. A. and Hopkins, H. G. "The Forest Soil of the Douglas Fir Region, and Changes Wrought Upon It by Logging and Slash Burning." Ecology. Vol. 18, No. 2, April, 1937. 2Sudworth, G. B., "Forest Trees of the Pacific Slope." U. S. Department of Agriculture, Forest Service, 1908.

3Isaac, L. A., "Measured Flight of Seed of Douglas Fir and Its Associates." Pacific Northwest Experiment Station, 1937.

4Isac, L. A., "Highlights of Douglas Fir Natural Regeneration." Forest Research Note No. 21, Pacific Northwest Experiment Station, 1937.

sBusgen, M. and Munch, E. "The Structure and Life of Forest Trees," English translation by Thomas Thomson. Chapman and Hall, Ltd., London, 1929.
} 
the period of flowering, thus preventing pollination, may spoil what would otherwise be a heavy yield of seed. It can be seen however, that if we could with even a fair degree of accuracy, predict the volume of seed production, the problem of management would be simplified.

It is rather to be feared that our present method of evaluating seed crops, through the medium of Ranger reports, is far from attaining reasonable accuracy. It is realized that the press of administrative duties render it difficult for Rangers to present detailed reports on the reproductive cycle for the species occurring in their districts, but it is felt they should be asked to base their reports on the volume of cone production on more specific observation than is usually made. A definite classification for seed yield should be prepared and the observers initiated in its use. The study of seed yield should, as soon as possible, be extended to include notation of quality of seed, time of flowering, influence of climatic factors, particularly during the period of flowering, and entomological or phytopathological factors affecting seed production.

(ii) Groups of seed trees

Occasional patches of seed trees varying in size from one to twenty acres remain after logging and burning. These are either ridgetop types of non-merchantable fir, or swamp types of cedar and hemlock. The former rarely occur and are to some extent effective. The latter are more common and are practically useless, since the cedar and hemlock seedlings which occasionally result are unable to exist on the dry, sandy loams which slope down to the swamps. When cedar seedlings do establish they make very slow growth. In the case of the "islands" of non-merchantable fir, reproduction does become established, to a distance of 10 chains to the south, and 2 chains to the north of the seed trees. This type of timber consists of trees too small for saw-logs, too misshapen for ties or piling, and invariably is fire damaged. Their crowns are thin and poor, and while their seed is apparently just as viable as that from healthy specimens, the amount produced is very small. The fact that the seedlings surrounding the group are nearly all of an age denoting establishment immediately after the burn, indicates that the parent trees, excited by fire injury, produced large quantities of seed immediately after the burn, but ever since had had too hard a task struggling for survival, to spare energy in seed production.

(iii) Individual seed trees

Individual trees left by logging on this operation are small, understory hemlock and cedar poles, the latter being too defective or too small to be marketable. There may be 10 to 30 of these trees left to the acre, usually 
damaged to some extent by logging - the very poorest type of seed producer. For their size and condition they bear surprisingly large amounts of seed, practically none of which germinates and becomes established. References are common in silvical literature of instances where hemlock and cedar occur prolifically over slash areas, and it has been suggested that such young growth results from seed cast by the understory which survives logging. This I consider to be true. The failure of similar conditions to exist on the study area, is attributed to the moisture factor. It is probable that many seeds do germ. inate, but that they are unable to obtain sufficient moisture from the duff, during those critical days when the root is struggling to reach mineral soil. As a result the seedlings perish ${ }^{1}$.

\section{(4) EFFECT OF GROUND COVER}

Ground cover existing on any logged-over area exercises two conflicting effects on regeneration. It offers shade to the young seedling, which as Isaac has determined, serves not only to reduce day-time soil surface temperatures, but to retard loss of warmth at night ${ }^{1}$. On the other hand such cover competes with reproduction for the available water and food supply. In this connection it is obvious that dead shade in the form of logging slash is superior to plant cover. It has been observed that slash cover may conceivably be so heavy that it may offer mechanical interference to young trees, but such a condition is not found on any portion of the study area. The live cover existing, except in the case of one plant, was never observed to be having a determinable effect on coniferous growth. Large portions of the land studied are well covered with willow and alder, a type of growth which would preclude the establishment of fir reproduction, although favouring that of cedar ${ }^{2}$. Opportunity to corroborate this was lacking, since factors other than that of competing cover, notably a lack of seed supply, prevented the establishment of young growth under such circumstances.

Other plants commonly found include bracken (Pteris aquilina), salal (Gaultheria shallon), fireweed (Epilobium angustifolium), various Compositae, (particularly Agoseris sp.), blackberry (Rubus macropetalus), and many of lesser importance in order of occurrence.

The plant mentioned as having an injurious effect on coniferous reproduction has been spoken of earlier in this report. This, the Hairy Cap Moss (Polytrichum juniperinum), is found all over the study area, wherever

\footnotetext{
1vid. Barr, P.M., "The Effect of Soil Moisture on the Establishment of Spruce Reproduction in British Columbia." Yale University: School of Forestry Bulletin No. 26, 1930. IIsaac, I. A., Forest Research Notes, No. 21, P. N. W. Experiment Station, 1937.

2Howe, D. C., "The Reproduction of Commercial Species in the Southern Coastal Forests
} of British Columbia." Commission of Congervation, 1915. 
fire has cleaned the ground to mineral soil. It is also found when fire has run into green timber, though under trees it does not grow so profusely as in the open. The moss was observed well into the virgin forest on mineral soil exposed by a wind-thrown tree, but is nevertheless thought to be a plant favoring soil sites whose $\mathrm{pH}$ concentration is circumneutral, a condition which results on these areas as a result of burning.

An illustration of the rapidity and thoroughness with which it will take over a soil surface is offered on land logged in 1928-29, burned in 1930 and again in 1931. The site is comparatively poor, the soil a shallow, sandy gravel, with many small boulders. Nevertheless the original stand yielded $40 \mathrm{M}$. f.b.m. per acre from small but densely grown trees. Immediately adjacent to this area and to the northeast a solid block of fir and cedar timber stood for five years following the burning of the logged off land in question. 1931-3233 were good seed years, the area lies directly in the path of the prevailing autumnal wind, yet satisfactory stocking in Douglas fir is present for barely 150 feet from the edge of where the timber stood. The soil surface is now from $75 \%$ to $100 \%$ covered with moss. The failure of reproduction to extend farther is attributed to the fact that the moss, following a hard burn, took over the ground surface very quickly after the fire, choked out many of the seedlings already established, and prevented the establishment of all but a few trees in successive years. This is confirmed by the fact that the bulk of the reproduction was established the year following burning before the moss acquired control.

The poor quality of the soil is not thought to be the factor limiting the extent of reproduction, since on a nearby site with equally poor soil, where reproduction resulted from a ground fire before logging the young growth is abundant and growing well.

Further evidence of the inability of seedlings during the early critical period of their development to survive the intense competition provided by the moss, was observed in that many of the plants were growing immediately against a small boulder, the seed having fallen on the interstice between the matted moss and the stone, and consequently had been able to establish its roots quickly in mineral soil. Occasionally a particularly vigorous seedling is able to penetrate the moss, survive the competition for food and moisture in the first inch or so of soil, and persist in its growth. It is probable that much of the seed falling on the moss, germinates, then dies within a few days because of its inability to make sufficiently intimate root contact to permit of its utilization of the moisture held within the moss. Verification of this fact would be valuable, and experimentally simple. 
A further example of the rapidity with which this plant will cover the soil surface is afforded on an area which was burned in 1935. Two years later from 40 to $50 \%$ of the surface had been occupied by this moss. In this case the burn was light, barely exposing mineral soil.

There is evidence too, that after a period of years, possibly due to the leaching of plant foods to lower soil zones the moss cover tends to break up and disappear. On land swept by the slash fire of 1928, burned clean by a hot fire, the moss cover occurs in irregular patches, occupying about a third of the ground surface, when it is probable that it had formerly been much more prevalent.

\section{(5) EFFECT OF SOIL CONDITIONS}

The character of the soil is considered to have had no appreciable influ. ence on the success of reproduction. A portion of the study area was the subject of a soil survey conducted in 1931 by Mr. C. C. Kelley for the Provincial Department of Agriculture. In his report it is stated that an aggregate sample of several hundred borings, taken to a depth of nine inches, shows the soil to be slightly acid, with phosphoric acid, potash, and total nitrogen present in proportions sufficient to classify the soil as "normal" accord. ing to the ratings of Professor Maerker. A few check samples were taken during this study which confrmed this analysis. On a six year old burn the acidity ranged from slightly acid to slightly alkaline, with low quantities of nitrogen, $(0.5-0.7 \%)$ and high proportions of lime $(2.2 \%)$. Samples taken 500 feet distant on soil lightly touched by a ground fire, and on which timber had stood less than a year previous to sampling, gave a slightly acid reaction, contained a favorable quantity of total nitrogen $(.18 \%)$, fair amounts of potash and phosphoric acid, and a high proportion of lime (1.7). The acid reaction is diffcult to reconcile with the lime proportion, and is a phenomenon noted, but not thoroughly explained, by Kelley in his 1931 survey.

It would appear that a greater degree of acidity would be more favorable for establishment and growth of reproduction. But the proof of soil productivity is in the crop, and samples from land bearing twelve year old trees growing 18 inches a year indicate the soil to be neutral or but very slightly acid.

The mechanical composition of the soil is in general that of a sandy loam. On higher benchlands the proportion of silt and clay varies between 12 and $20 \%$ with gravel over $2 \mathrm{~mm}$. running as high as $60 \%$. In places, stones or small boulders are plentiful, exercising an effect on the establish-

1 Kelley, C. C. A soil survey conducted by the Provincial Department of Agriculture, 1931. 
ment of reproduction in proportion as their occurrence lowers the area of soil surface presented to falling seed.

Varying intensities of burning have had no apparent effect in breaking down soil structure. The chemical composition of the soil has doubtless been altered particularly by an increase immediately after the burn, in the quantities of available nitrates, and by a change toward alkalinity in the hydrogen ion concentration, but not to the extent of such change becoming a limiting factor in the establishment of new growth. The purpose of this investigation did not include intensive soil examination, and therefore no information was gained on changes effected in chemical composition of virgin forest soil on being exposed to fire. It is possible that slash burning may result in a loss to the soil of considerable quantities of plant nutrients. The important point is that on the study area, the soil exposed by burning contains sufficient plant food to support reproduction at a satisfactory growth rate. If the duff and humus preventing the establishment of seedlings could be removed by some other method than by fire, the possible saving of soil nutrients might result in extension of the limits for satisfactory regeneration from the source of seed, and in increased growth, but under present conditions the use of fire is the only feasible means of exposing the mineral soil.

In other districts within the fir region the effect of fire on the soil may be distinctly harmful. The necessity for research into changes in the soil resulting from slash burning has already been noted.

\section{(6) ENTOMOLOGICAL AND PATHOLOGICAL EFFECTS}

Although there is no fungus attack in evidence, the young growth is suffering from an insect infestation. The attack, centred on trees up to six years of age, is made by plant lice of the genus Adelges. This aphid, Adelges cooleyi, uses as its primary host tree the occasional Sitka spruce occurring on bottomlands, on which tree its activities result in the formation of characteristic cone-like galls on branch terminals. On the alternate host, Douglas fir, the insect manifestation is the small woolly patches on the needles of the tree. The insects feed upon the needles, and occasionally on the twigs and bark. They occur in profusion on many young trees, their activities being evidenced in a discoloration of the needle where they have fed. The attack results in a premature dropping of the affected needles, although no instance of total defoliation was seen. Undoubtedly such attacks retard growth, and if repeated in successive years, may cause the death of many trees. The only present determinable economic loss results in the cutting of Christmas trees which have been infected, and which, very shortly after cutting, lose their needles. If the infestation thus checks the cutting of Christmas trees, without 
materially damaging the growing stock, the aphid attack may be a blessing in disguise.

\section{(7) EFFECT OF MECHANTCAL INJURY BY ANIMALS}

Retardation of growth and deformation of the tree are occasioned in some instances by deer and cattle browsing. Probably ten per cent. of the young trees at some time have had the new spring growth at the terminal of the leader nibbled by deer. Where cattle have ranged, similar damage, though to a lesser extent, was noticed. It was observed that reproduction which had existed for some years under timber was more damaged than that which had come in on open sites. In the former case the trees, as a result of their more sheltered position, flaunted their advance growth at a time when edible greenery was at a premium among the deer population-with unfortunate results. In some instances the terminal bud and lateral buds have been nipped off, presumably by birds or squirrels, with resulting deformation of the tree.

The detrimental effect that the depredations of squirrels have upon the yield of Douglas fir seed is well known. It has been estimated that in years of poor or medium seed crops all the seed may be eaten by squirrels or birds ${ }^{1}$.

The finding of an occasional squirrel hoard is an aid in cone collection, but despite this, and his aesthetic appeal, on the whole it would appear good forestry to agitate for the placing of a bounty on the head of that charming little scoundrel-the Western Red Squirrel.

A discussion of any phase of game management is beyond the scope of this report and the statement in the preceding paragraph is intended as provocation to research rather than recommendation. An investigation into the damage done by squirrels, and a determination of this animal's relative importance in the biologic balance, would be of definite value to the Forest Service. We cannot ignore the part played by animals and in particular by the squirrel, any more than we can disregard the many other factors previously discussed. We must realize that success in our efforts to secure natural regeneration depends upon diligent research into the many factors involved in the problem. Slash burning is not a magic formula. It will be successful only in certain instances and then only when each agent affecting such success is appreciated for its importance. There may be occasion when depletion of the seed supply by squirrels, or damage to the growing stock by other animals, is the limiting factor. Thought should be given to the prepara-

1Isaac, L. A. "Highlights of Douglas Fir Natural Regeneration." Pacific Northwest Experiment Station, Portland, 1937. 
tion of a program of research into questions of game management, and it is suggested the squirrel and his activities receive first attention.

\section{(8) EFFECT OF TOPOGRAPHY}

In many of our Coast forests topography has a very definite effect on the success of tree growth, and on the establishment of reproduction follow. ing logging. On areas where appreciable slopes occur, cr where the contour of the ground is broken by streams, depressions, and hills, successful estab. lishment of new growth may be largely determined by the aspect of the various hillsides, and in some degree by erosion. Such conditions are not found on the area examined. The ground consists of low benchlands sloping easily to the seas, with elevations varying from 100 to 700 feet. In no case is aspect a factor limiting regeneration, nor is erosion evident.

\section{(9) EFFECT OF CLIMATE}

Although this discussion of the effect of climate on regeneration follows those dealing with other factors, the place of this agent is generally recog. nized as being first in importance on any list of factors influencing tree growth. In particular, climate, through the medium of its most important components, heat and moisture, exercises the most marked effect in the early period of a tree's growth, from germination to the sapling stage. However, in the course of this study it soon became apparent that factors which may be described as mechanical, i.e., fire and logging method, exercised far greater influence than any others. An increase in the ratio of any agent, as stated in Mitscherlich's conception of the law of minimum, will result in the improvement of the whole, but in inverse proportion to the quantitative presence of the factor in the original balance. Climate in this region is not an agent of first importance in limiting regeneration. Speaking figuratively we have plenty of this factor to ensure reproduction, though in a normal year some seedlings will die from lack of moisture. An increase in favorableness of a growing season would result in survival of many otherwise doomed plants. But if we were to increase the amount of seed falling on the area, other conditions being suitable, the benefit to the yield would be much greater in proportion than was that resulting from the improvement in climate. It is apparent then that we can most readily influence the success of regeneration by attention to factors over which we can exert positive control, and that climatic agents are of relative unimportance.

The climatic record of the district as compiled at the nearest weather station indicates a growing climate particularly favourable for our coastal species. Average rainfall in the past 22 years has been 45 inches-average snowfall, $32 \frac{1}{2}$ inches, making a total precipitation of 48 inches. More im- 
portant than the average however, is the deviation from it. Examination of average monthly precipitation statistics shows distribution to be rather erratic, ranging from almost nine inches in December to little more than an inch in July. June and July are further irregular in that with no apparent cycle, monthly rainfall has varied from one-half to four inches.

Records of temperature are only available for a point some twenty miles to the south, but are considered reasonably indicative of conditions on the study area. On this basis, a fourteen year average gives a mean annual temperature of $48^{\circ}$ in July. Extremes vary from $20^{\circ}$ to $90^{\circ}$. Relative humidity during the summer months occasionally drops to $20 \%$.

A study of seedling survival under these conditions was beyond the scope of this investigation. Observation of effect of climatic factors was incidental, and further hampered by 1936 being rather a poor seed year offering few examples of the progress of this year's seedlings. Those found dead or in obvious distress, had quite evidently suffered from lack of moisture, the greatest mortality occurring in July, which this year was rather drier than usual. In no instance were heat lesions observed on dead or dying plants. Late spring frosts are expected to take a yearly toll but extent of damage from this cause was not determinable. Mortality attributable to this moisture factor is intimately integrated with the factor of ground cover and in particular with the effect exerted by moss. A measure of the degree of influence exercised by each could be determined by check plots kept free of moss, and on others on which no plant cover other than coniferous, is permitted. The importance of heat as an agent limiting success of reproduction would then become increased, and must be considered.

When one gives thought to the possibility of the study suggested, emphasis becomes necessary on the integration of factors affecting tree growth. A change in one, no matter what its ranking in the environmental whole, affects to some degree the yield determined by the whole. In this article factors have been treated separately purely for descriptive purposes. Technically the inter relation of these agents makes it impossible to consider each as one individual problem. Practically there is much that we can do. The factors exercising the most deleterious effect on regeneration are man-made, and can be man'controlled. By instituting a more favourable method of cutting and by protecting cut-over lands from repeated fires we can materially increase our acreage of reforested land. 


\section{SUMMARY AND CONCLUSION}

The area examined lies in the Esquimalt and Nanaimo Railway Land Grant, on the east coast of Vancouver Island. The facts of first importance determined by the study are as follows:

(1) Of 19,981 acres logged in the past 17 years, $5.4 \%$ are satisfactorily stocking-94.6\% are unsatisfactory. Of 14,503 acres logged to 1933 , $6 \%$ are satisfactorily stocked-94\% are unsatisfactorily stocked. Of 3,204 acres logged to $1927,10 \%$ are satisfactorily, and $90 \%$ unsatisfactorily stocked.

(2) 589 acres of fully stocked ( $55 \%$ of total acreage stocked) occur on areas of unburned slash. In every case this results from a surface burn prior to logging.

(3) Reproduction is unsuccessful in areas of unburned slash when no fire has occurred before logging.

(4) Repeated fires are an important factor in the failure of the area to become restocked. 4,000 acres have been burned two or more times.

(5) 1,500-2,000 acres of timberland are skidder logged each year.

(6) Seeding from seed trees on slash-burned lands is successful for 10 chains in the direction of prevailing northerly winds -2 chains in the opposite direction.

(7) Patches of swamp type, non-merchantable timber left in the course of logging are of little or no value as a source of seed.

(8) The occurrence of a moss, Polytrichum juniperinum, on burned lands, is a factor limiting the establishment of reproduction.

The picture of some 20,000 acres, $95 \%$ of which is not satisfactorily stocked, is not a pretty one. This is extremely accessible, easily logged, highly productive forest land. The problem of once more putting it into production is as discouraging as it is important. Areas containing even a few trees per acre may be expected to increase slowly their percentage of stocking, as the present trees begin producing seed, but this is a slow process, hindered by the rapid spread of willow and alder and the building up of a ground litter through which each year's seed will find it progressively harder to penetrate. If fire can be kept out the situation in time will correct itself.

Perhaps in a hundred years this land will again support a forest cover. Insofar as this particular area is concerned we can do nothing but keep fire out of it, perhaps plant a little, and sit down to wait. Meanwhile the company in question is attempting a solution by selling the logged-off land to settlers. Selected parcels of land are certainly capable of producing agricul- 

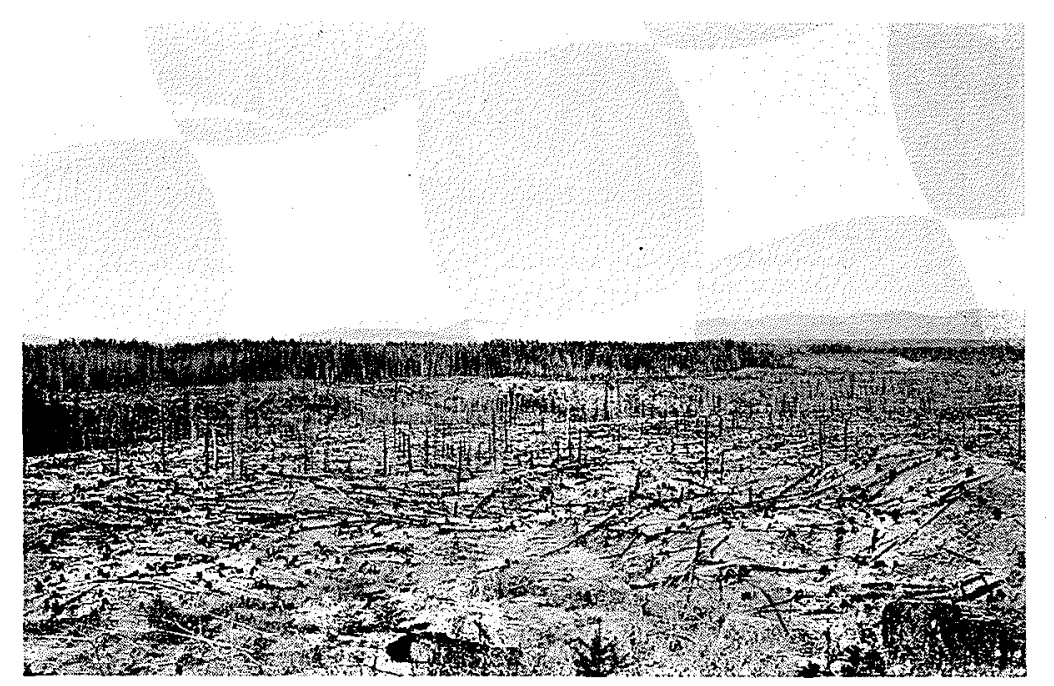

Photo: Photographic Surveys, 1935.

Looking northeast from Setting No. 26, Block 28, Logged 1929 and 1928, burned 1930 and 1931. Reproduction-nil.

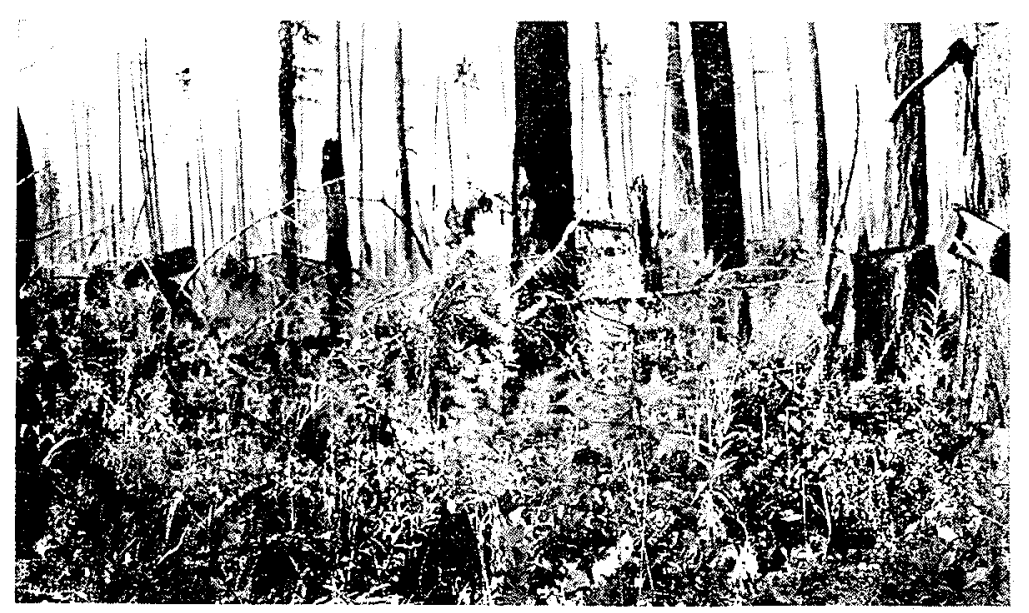

Setting No. 62, Block 28. Logred 1937, surface burned 1931. Fir-hemlock reproduction, 1,000 per acre, $4-5$ years old in unburned slash. 


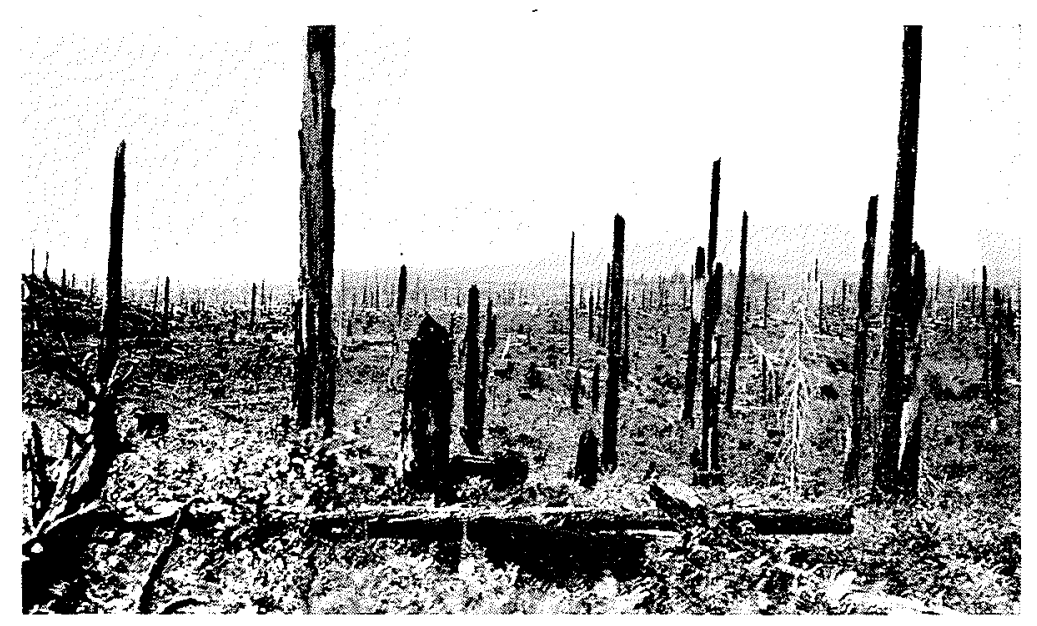

Setting 77, Block 28, Logged 1931. Burned 1931. Fir reproduction less than 50 trees per acre. Heavy cover of bracken, fireweed and salal. Original stand of fir yielded 80,000 f.b.m. per acre.

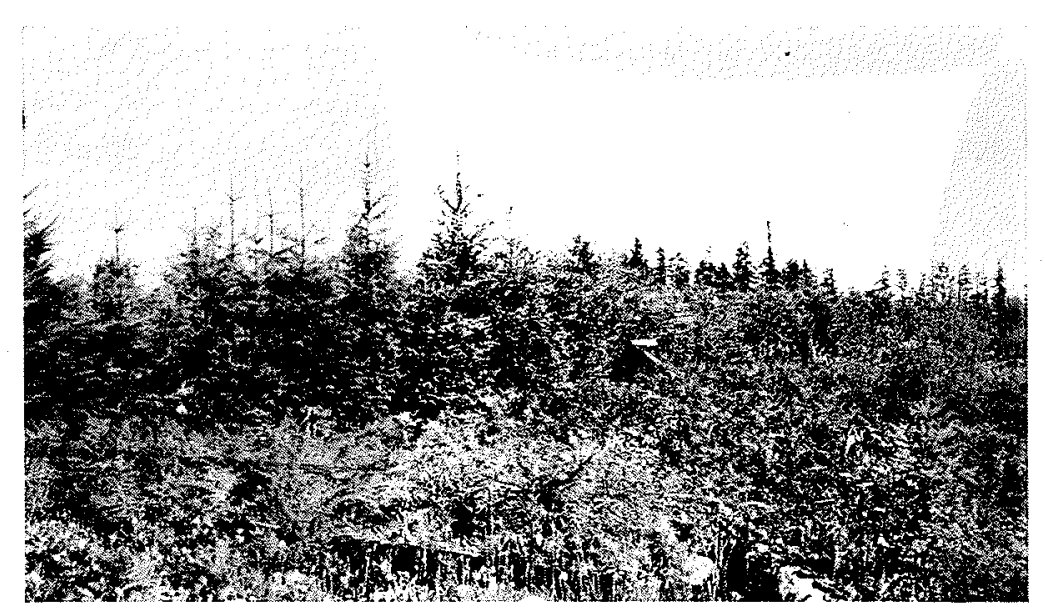

Setting No. 11A, Section 19. Fir reproduction 8 years old established as a result of a surface burn in 1928 . Logged in 1929, fire in 1931 destroyed young growth which had occupied foreground. Ground cover is bracken and false dandelion. 
tural crops, with small fruits in particular promising to do well. This policy is to be commended insofar as such settlement is conducive to the establishment of a permanent community whose economic stability, resting on the double foundation of proceeds from farming and from work in the logging camps, is of advantage to the company and to the province as a whole. But the cost of clearing is excessive, agricultural values are barely marginal, and the prediction is made that the greater part of this land will gradually revert to the use for which it is pre-eminently fitted-the growing of trees.

This study has been entirely concerned with the condition of the loggedoff land and the definition of contributive factors. In logical sequence further study should be devoted to problems of logging operations with the idea of incorporating into future cutting plans the knowledge that has been gained. Much remains to be done in the realm of basic research into silvicultural questions, which in this article have been little more than indicated. But while this intensive investigation is proceeding, there are problems in the economics of timber extraction which would arise on the application of silvicultural principles and which demand solution. It is suggested that the ways and means of applying these principles receive our immediate attention, and the co-operation of the industry be sought to that end. 